CARDIOVASCULAR MEDICINE

\title{
Benefit of glyceryl trinitrate on arterial stiffness is directly due to effects on peripheral arteries
}

A L Pauca, N D Kon, M F O'Rourke

Objective: To determine how the vasodilator glyceryl trinitrate (GTN) alters arterial stiffness and improves left ventricular afterload.

See end of article for authors' affiliations

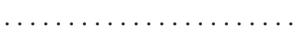

Correspondence to: Dr Michael F O'Rourke Suite 810, St Vincent's Clinic, 438 Victoria Street, Darlinghurst, NSW 2010, Australia; M.ORourke@ unsw.edu.au

Accepted 2 February 2005 Published Online First 10 March 2005
Methods: Ascending aortic pressure waves were measured with fluid filled catheters of high fidelity in 50 patients undergoing cardiac surgery, before cardiopulmonary bypass, both before and after intravenous infusion of GTN. In all 50 patients, wave reflection was identifiable as a secondary boost to late systolic pressure, permitting the pressure wave to be separated into a primary component, attributable to left ventricular ejection and properties of the proximal aorta, and a secondary component, attributable to reflection of the primary wave from the peripheral vasculature.

Results: GTN infusion caused no change in amplitude of the primary wave (mean (SD) 0.0 (1.4) mm Hg, not significant) but substantial reduction $(14.6(9.6) \mathrm{mm} \mathrm{Hg}, \mathrm{p}<0.0001)$ in amplitude of the secondary reflected wave. Fall in mean pressure was attributable to a mix of arteriolar and venous dilatation, with relative contributions unable to be separated.

Conclusion: Favourable effects of GTN on arterial stiffness can be attributed to effects on peripheral muscular arteries, causing reduction in wave reflection. Results conform with previous invasive studies on vasodilator agents and their known effects on calibre and compliance of muscular arteries. dis ncreased death and disability rates from cardiovascular disease in older people is associated with, and attributable to, increased systolic and pulse pressure, causing greater load on the heart and greater tension in arterial walls. ${ }^{1-5}$ The prime cause of increased systolic and pulse pressure is increased stiffness of the aorta and central elastic arteries. ${ }^{67}$ Such awareness has led to efforts to develop drugs that may have specific effects on arterial stiffness and thus the potential to lower pulsatile pressure while maintaining mean pressure and normal perfusion of vital organs. ${ }^{8}$

While beneficial effects on pulse pressure and arterial stiffness have been reported for different drugs there is no consensus on how these drugs act ${ }^{9-16}$ or on how their effects should be measured. ${ }^{17}$ Recent major publications have focused on compliance of the whole arterial tree for the advanced glycation end product cross link breaker AT711 ${ }^{18}$ and on ascending aortic characteristic impedance for omapatrilat and other drugs. ${ }^{19}{ }^{20}$ However, other recent and earlier studies had focused on the ability of nitrates, ${ }^{6} 141621-23$ calcium channel blockers, and angiotensin converting enzyme inhibitors to reduce wave reflection through an increase in calibre and distensibility of peripheral small arteries. Such studies were performed during cardiac catheterisation or non-invasively, ${ }^{9-15} 22$ with generation of central from peripheral waveforms by means of generalised transfer functions. ${ }^{212425}$ The validity and relevance of these have been questioned. ${ }^{19}{ }^{20}$ The present study was undertaken to examine the effects of intravenously infused glyceryl trinitrate (GTN) on the amplitude of the reflected pressure wave and on central aortic pulse pressure recorded directly in a large group of patients with cardiovascular disease, before open heart surgery.

\section{METHODS}

Similar equipment and methods were used as in previous studies including anaesthetic agents and the matched fluid filled pressure systems. ${ }^{26-28}$ After the study was approved by the institution's clinical research practices committee, written consent was obtained from 50 consecutive patients who were to undergo cardiac surgery. Patients were studied before being placed on cardiopulmonary bypass. Radial artery pressure was routinely established before induction of anaesthesia through a $5.1 \mathrm{~cm} 20$ gauge Teflon catheter. Recordings for this study were taken 60-90 minutes after anaesthesia had been established and after preparations for aortic cannulation had been completed. Ascending aortic pressure was recorded at the site prepared for bypass cannulation through a catheter identical to that used at the radial artery. Both catheters were attached to individual high pressure tubes $91.4 \mathrm{~cm}$ long. These had been attached to matched Transpac IV transducers (Abbott Critical Care Systems, Abbott Laboratories, North Chicago, Illinois, USA). Frequency response and damping coefficient were obtained by the flush method at the beginning and end of the recording period in each patient and were confirmed to have a natural frequency $>20 \mathrm{~Hz}$ and damping coefficient $\geqslant 0.2{ }^{28}$ All transducers were calibrated statically with a mercury manometer and maintained at the same level. Matching was confirmed as previously described. ${ }^{27}$

After control recordings of aortic and radial pressure had been obtained, GTN was infused at an average dose of $6 \mu \mathrm{g} /$ $\mathrm{kg} / \mathrm{min}$ for $10-30$ seconds, up to $16 \mu \mathrm{g} / \mathrm{kg} / \mathrm{min}$ for $5-10$ seconds, aiming at lowering systolic radial artery pressure to $100 \mathrm{~mm} \mathrm{Hg}$. Further recordings of aortic and radial pressures were taken at the peak of the GTN effect. Recordings were obtained simultaneously during a period of 2-5 minutes. Once the study was completed, the catheter was removed and the surgeon proceeded with the aortic cannulation. Data were recorded by a Siemens medical systems recorder with linear frequency response up to $500 \mathrm{~Hz}$. Mean arterial pressure was obtained by electronic integration. Simultaneous recordings of aortic and radial pressure waves were analysed off line.

Paired aortic pressure waves over 10 second periods were compared before and after GTN infusion. Waveform types were assigned the labels of type A, B, or C by visual inspection 


\begin{tabular}{|c|c|}
\hline \multicolumn{2}{|c|}{$\begin{array}{l}\text { Table } 1 \text { Descriptive statistics for the } 50 \\
\text { patients studied }\end{array}$} \\
\hline Age (years) & $64.6(11.2)$ \\
\hline Weight (kg) & $81.0(14.7)$ \\
\hline Height $(\mathrm{cm})$ & $172(8.4)$ \\
\hline Ejection fraction (\%) & $50(13)$ \\
\hline Packed cell volume & $0.32(0.049)$ \\
\hline Core temperature $\left({ }^{\circ} \mathrm{C}\right)$ & $35.8(0.7)$ \\
\hline $\mathrm{PaCO}_{2}(\mathrm{~mm} \mathrm{Hg})$ & $38.5(1.4)$ \\
\hline $\mathrm{PaO}_{2}(\mathrm{~mm} \mathrm{Hg})$ & $246.4(94.5)$ \\
\hline History of hypertension & 47 \\
\hline CABG planned & 49 \\
\hline Cardiac output (l/min) & $4.3(1.4)$ \\
\hline \multicolumn{2}{|c|}{$\begin{array}{l}\text { Data are mean (SD) or number. } \\
\mathrm{CABG} \text {, coronary artery bypass grafting; } \mathrm{PaCO}_{2} \text {, arterial } \\
\text { carbon dioxide pressure; } \mathrm{PaO}_{2} \text {, arterial oxygen pressure. }\end{array}$} \\
\hline
\end{tabular}

according to Murgo et $a^{29}$ depending on the amplitude of systolic pressure augmentation to pulse pressure.

The patient group comprised 42 men and eight women with ages ranging from 41-87 years. All but one (mitral valve disease) had coronary artery disease and were to undergo coronary artery bypass or valve repair surgery. All but three were being treated for hypertension. Table 1 presents the details of the 50 patients.

\section{Statistical analysis}

We used a paired two tailed $t$ test to evaluate the effect of treatment on the aortic primary wave (amplitude from wave foot to first systolic wave shoulder, ${ }^{29}$ the primary component), aortic augmentation (amplitude from shoulder to wave peak, the secondary component, ${ }^{29}$ ), and delay of the wave foot between aortic and radial pulse. All data were expressed as mean (SD).

\section{RESULTS}

\section{Baseline}

Figure 1 shows typical radial and aortic pressure waves as recorded simultaneously before nitrate infusion. In 46 patients, the amplitude of the radial pressure wave was clearly greater than the aortic and the foot of the radial wave was delayed in relation to the foot of the aortic pressure wave in all 50 patients. Two localised distinct peaks, a first (P1) and second peak (P2), were seen in 45 aortic pressure waves but in only 21 of 50 of the radial pressure waves.

The aortic pressure wave showed $\mathrm{Pl}$, or the first component, as a shoulder on the ascending part of the wave with $\mathrm{P} 2$, or the second component, forming the apex of the wave. In contrast, in the radial artery the first component or P1 usually constituted the peak of the wave, with P2, when apparent, a late systolic shoulder on the falling limb of the wave before the incisure. According to the classification of Murgo et $a^{29} 48$ aortic control pulse waves were type A, in which $(\mathrm{P} 2-\mathrm{P} 1) \div(\mathrm{P} 2-\mathrm{P} 0)$, where $\mathrm{P} 0$ is the wave foot, was $>0.12$, and only two were type $\mathrm{B}$, in which $(\mathrm{P} 2-\mathrm{P} 1) \div(\mathrm{P} 2-\mathrm{P} 0)$ ranged between $0.00-0.12$. None were type $\mathrm{C}$, in which $(\mathrm{P} 2-\mathrm{P} 1) \div(\mathrm{P} 2-\mathrm{P} 0)$ was less than zero.

\section{Treatment}

GTN infusion led to a fall in arterial pressure but did not change the relations between aortic and radial systolic, diastolic, and mean pressures from those under control conditions (table 2). While the mean and diastolic pressure differences between the two sites were small, those for systolic, pulse pressure, and end systolic pressure were large (table 2), as under control conditions and as previously described. ${ }^{26} 27$

GTN greatly changed the shape of the aortic and radial pressure waveforms. In the aortic pressure tracing, the main change was a decreased $\mathrm{P} 2-\mathrm{Pl}$ (fig 2) and in the radial tracing the second shoulder ( $\mathrm{P} 2)$, present in only 21 patients, disappeared in 18 and the location of the incisura became blurred.

The effect on aortic augmentation $(\mathrm{P} 2-\mathrm{P} 1)$, primary wave (Pl-P0), and PP with GTN was clear in all observations (table 3). Pl-P0 did not change (28.7 (8.9) to 28.7 (9.0); fig 3, left), whereas P2-P1 was reduced to almost one third (23.0 (11.5) to 8.4 (7.5), p $<0.0001$; fig 3, right).

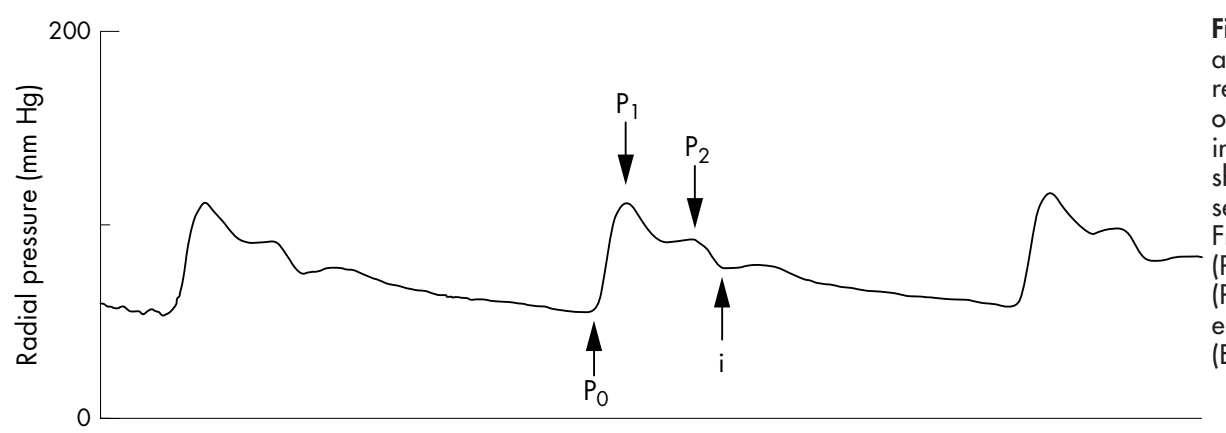

Figure 1 Typical radial (top) and aortic (bottom) pressure waves recorded simultaneously in a 68 year old patient. Features of the waves: $i$, incisura; $\mathrm{PO}$, wave foot; $\mathrm{Pl}$, first peak or shoulder during early systole; P2, second peak or shoulder in late systole. From these features, the pulse pressure (PP), amplitude of the first systolic wave (P1-P0), augmentation (P2-P1), and end systolic pressure at the incisure (ESP) can be measured.

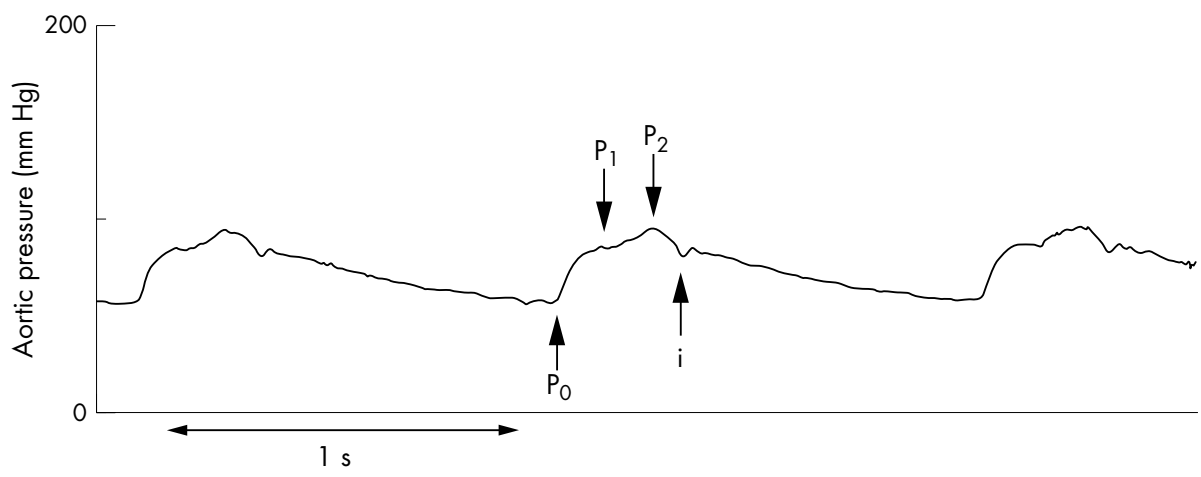


Table 2 Differences in aortic and radial pressures on insertion of the radial artery cannula (initial) under baseline conditions and after glyceryl trinitrate

\begin{tabular}{llllll}
\hline & SAP $(\mathrm{mm} \mathrm{Hg})$ & DAP $(\mathrm{mm} \mathrm{Hg})$ & MAP $(\mathrm{mm} \mathrm{Hg})$ & PP $(\mathrm{mm} \mathrm{Hg})$ & ESP $(\mathrm{mm} \mathrm{Hg})$ \\
\hline Initial & $153(19)$ & $76(12)$ & $101(12)$ & $78(19)$ & NA \\
Baseline & & & & & \\
$\quad$ Radial & $127.7(15.0)$ & $61.2(8.8)$ & $83.8(9.8)$ & $66.9(13.8)$ & $78.7(11.3)$ \\
$\quad$ Aortic & $114.5(16.2)$ & $62.3(9.0)$ & $84.8(10.0)$ & $52.1(15.0)$ & $90.5(11.6)$ \\
$\quad \begin{array}{l}\text { Difference } \\
\quad \text { Value }\end{array}$ & $13.2(9.2)$ & $-1.2(2.5)$ & $-1.1(1.8)$ & $14.8(9.5)$ & $-11.8(4.5)$ \\
$\begin{array}{l}\text { Glyceryl trinitrate } \\
\text { treatment }\end{array}$ & $<0.0001$ & $0.0002^{*}$ & $<0.0001^{*}$ & 0.0001 & $<0.0001$ \\
$\quad$ & & & & & \\
$\quad$ Radial & $103.4(13.8)$ & $51.6(9.5)$ & $67.7(10.2)$ & $51.8(11.4)$ & $61.2(10.8)$ \\
$\quad$ Aortic & $89.6(12.0)$ & $52.5(9.3)$ & $68.3(9.9)$ & $37.2(11.7)$ & $70.8(11.1)$ \\
Difference & $13.8(8.4)$ & $-0.9(2.1)$ & $-0.6(1.8)$ & $14.6(8.4)$ & $-9.6(4.5)$ \\
p Value & $<0.0001$ & $0.0004^{*}$ & $0.018^{*}$ & $<0.0001$ & $<0.0001$ \\
\hline
\end{tabular}

Data are mean (SD).

DAP, diastolic aortic pressure; ESP, end systolic pressure; MAP, mean aortic pressure; NA, not applicable; PP, pulse pressure; SAP, systolic aortic pressure.

*Radial-aortic DAP and MAP differences, though statistically significant, were very small.

GTN infusion was associated with a delay in the foot of the radial compared with the aortic pulse wave (table 3 ), indicating a decrease in aortic to radial pulse wave velocity. However, the time from the aortic wave foot to the aortic systolic shoulder was not perceptibly increased (89 (11) ms before and 87 (12) ms after GTN). This has been taken as a measure of aortic pulse wave velocity ${ }^{30}$ and suggests no significant change in aortic stiffness, despite treatment with nitrate and a fall in aortic pressure. The foot of the reflected wave could not be identified with the same precision as the foot of the initial wave so that this interpretation needs be taken with great caution. Heart rate increased from 67 to 69 beats/min, with small changes in cycle length $(889$ (194) to $864(193) \mathrm{ms}$ ) and ejection period (312 (45) to 295 (44) ms, p $<0.01$ for both) and no change in diastolic period (579 (162) to 569 (161) ms).

\section{DISCUSSION}

Results presented here are for a large series of patients studied at surgery before cardiopulmonary bypass and receiving GTN by intravenous infusion. Findings are in line with those previously published for smaller series of patients that we and others have studied at cardiac catheterisation and receiving sublingual or intravenous nitrate. ${ }^{92141631}$ The predominant effect of nitrate was a substantial (63\%) reduction in aortic pressure augmentation (a measure of wave reflection from peripheral vessels), with no apparent effect on the primary aortic pressure wave (a measure of ascending aortic characteristic impedance). ${ }^{6}{ }^{11}{ }^{12}{ }^{14-16}$ In the present study, aortic flow was not measured during GTN infusion. For aortic characteristic impedance to have decreased with GTN, stroke volume would have had to increase correspondingly. There was no suggestion that this occurred or was likely to occur. Previous invasive studies that measured aortic flow and characteristic impedance or apparent phase velocity showed no or minimal change with nitrate, while all showed a reduction in wave reflection. $^{9-12} 141531$ The 20\% reduction in aortoradial delay did signify a decrease in pulse wave velocity in the upper limb, but this was associated with a similar $(20 \%)$ reduction in mean arterial pressure (and may be a largely passive effect). ${ }^{32}$ Results presented here for nitrates are also in line with those published for non-invasive, short term and long term studies in conscious subjects and in patients with arterial hypertension, which also showed a predominant effect in reduction of wave reflection as the explanation for reduction in calculated aortic systolic and pulse pressure. ${ }^{6} 162124$ Such studies also showed that the effect on wave reflection (explicable by arterial dilatation) can be achieved at far smaller doses than those required for venous and arterial dilatation with consequent reduction in mean and diastolic pressure. ${ }^{24}$ In this study a relatively high dose of GTN was administered, sufficient to cause venous and arteriolar, as well as arterial, dilatation. ${ }^{24}$

Data discussed above and those presented here can be explained and have been explained on the basis of dilatation of peripheral muscular arteries. Such dilatation in muscular arteries has been confirmed and has been shown to be associated with improved distensibility or compliance of these arteries. ${ }^{16} 233133$ Such widespread change in peripheral muscular arteries of the trunk and lower limbs readily explains the decrease in wave reflection from the more peripheral arteries, with such wave reflection being "trapped" in peripheral vessels and so unable to return to the heart and to boost systolic and pulse pressures. ${ }^{6} 1434$

These data provide an incentive and a challenge. The incentive is for pharmaceutical companies to develop new drugs that have an effect similar to that of GTN and that can reduce aortic pulse pressure and systolic pressure. They would have to have a minimal effect on mean and diastolic pressure but not have the other problems of nitrates, including poor GTN absorption and tolerance. ${ }^{24}$ The challenge is to those who, through exclusive consideration of Windkessel models, concentrate on the change in large

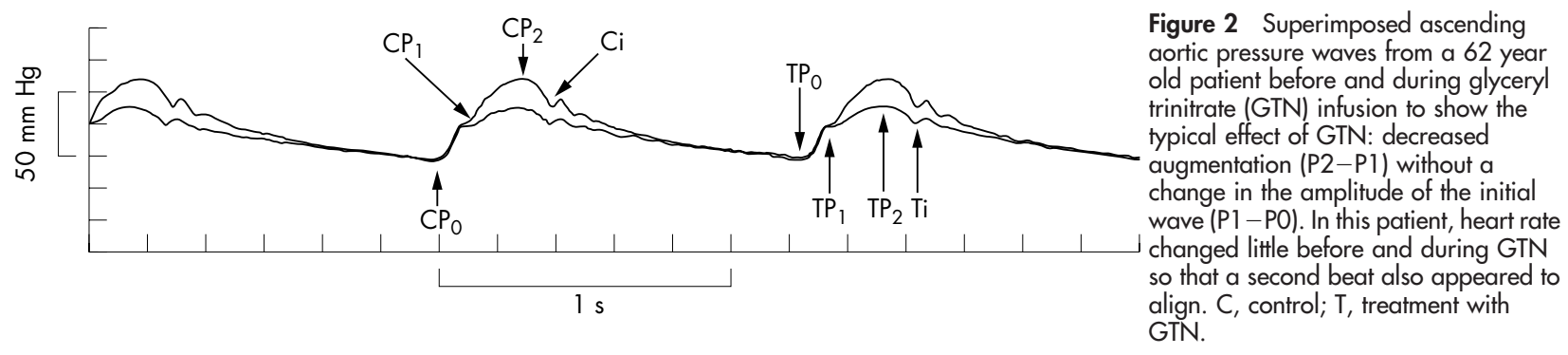


Table 3 Aortic baseline-treatment differences

\begin{tabular}{lllll}
\hline & Control & Treatment & Difference & P Value \\
\hline $\mathrm{PP}(\mathrm{mm} \mathrm{Hg})$ & $52.1(14.9)$ & $37.2(11.7)$ & $14.9(8.8)$ & $<0.0001$ \\
Augmentation (P2-P1) $(\mathrm{mm} \mathrm{Hg})$ & $23(11.5)$ & $8.4(7.5)$ & $14.6(9.6)$ & $<0.0001$ \\
$\mathrm{Pl}-\mathrm{PO}(\mathrm{mm} \mathrm{Hg})$ & $28.7(8.9)$ & $28.7(9.0)$ & $0.0(1.4)$ & $\mathrm{NS}$ \\
$\mathrm{A}-\mathrm{R}$ delay $(\mathrm{ms})$ & $69.8(13.5)$ & $86.2(14.7)$ & $-16.4(8.4)$ & $<0.0001$ \\
\hline & & & \\
Data are mean (SD). \\
A-R, aortoradial wave foot delay; NS, not significant; PO, wave foot; P1, first peak; P2, second peak.
\end{tabular}

artery stiffness and thus overlook or dismiss wave reflection in the reduction of aortic systolic pressure and left ventricular load.

Despite the reality of wave travel and reflection, so apparent in the data presented here, many investigators still use a Windkessel model of the arterial system ${ }^{35}$ (in which wave reflection cannot exist) to explain disease and drug effects on arterial stiffness. Input impedance is the long acknowledged full description of hydraulic left ventricular load presented to the left ventricle by the vascular tree. ${ }^{6} 293637$ This can be interpreted to show peripheral resistance (a measure of predominantly of arteriolar properties), characteristic impedance (a measure of proximal aortic stiffness), and wave reflection (to which all arterial properties contribute).

The present study describes the effects of nitrates on arterial stiffness and left ventricular load. Other vasodilator drugs appear to have similar but usually less potent effects on wave reflection and left ventricular load. ${ }^{13} 162238$ For these, effects on wave reflection appear to be dominant and explicable on the basis of drug action on peripheral muscular rather than on central elastic arteries. ${ }^{681638}$ Indeed, it is difficult to conceive how any vasodilator drug can have any effect on the disorganised and degenerate proximal aorta in older people with isolated systolic hypertension..$^{39}{ }^{40}$ In this study as in others ${ }^{14}{ }^{41}$ there was no evidence of any effect on aortic characteristic impedance with GTN. The present study takes a new look at an old drug and shows substantial benefit, which is attributable to a change in properties of muscular conduit arteries. The benefits of nitrate can exceed those of many newer drugs in the management of diseases such as angina, heart failure, and even hypertension. ${ }^{21}$ Such benefits can be explained in large part from analysis of the pulse waveform as practised by the father of cardiology, and the founder of Heart, Sir James Mackenzie. ${ }^{42}$

\section{Pl - PO (mm Hg)}

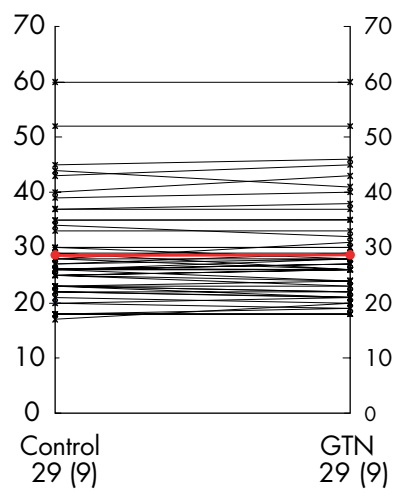

P2 - P1 (mm Hg)

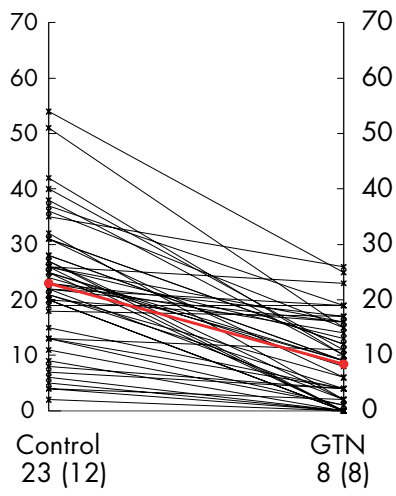

Figure 3 (Left) Amplitude of P1-PO in the ascending aorta before (left margin) and after GTN infusion (right margin) $(n=50)$. Mean values are denoted by filled circles and red lines. (Right) Amplitude of the augmented systolic pressure wave (P2-P1) in the ascending aorta before (left margin) and after infusion of GTN (right margin) ( $n=50)$.

\section{Authors' affiliations}

A L Pauca, Department of Anesthesiology, Wake Forest University School of Medicine, Winston-Salem, North Carolina, USA

N D Kon, Department of Cardiothoracic Surgery, Wake Forest University School of Medicine, Winston-Salem

M F O'Rourke, Department of Medicine, University of New South Wales, St Vincent's Hospital and Clinic, VCCRI, Sydney, Australia

Financial support provided by the Department of Anesthesiology, Wake Forest University School of Medicine, Winston-Salem, NC, USA and St Vincent's Clinic Foundation, St Vincent's Clinic, Sydney, Australia

Michael O'Rourke is a Director of Atcor Medical, manufacturer of systems for pulse waveform analysis.

\section{REFERENCES}

1 Franklin SS, Sutton-Tyrrell K, Belle SH, et al. The importance of pulsatile components of hypertension in predicting carotid stenosis in older adults. J Hypertens 1997; 15: 1143-50

2 Benetos A, Rudnichi A, Safar M, et al. Pulse pressure and cardiovascular mortality in normotensive and hypertensive subjects. Hypertension 1998;32:560-4.

3 Franklin SS, Khan SA, Wong ND, et al. Is pulse pressure useful in predicting risk for coronary heart disease? The Framingham heart study. Circulation 1999; 100:354-60.

4 Chobanian AV, Bakris GL, Black HR, et al. National Heart, Lung, and Blood Institute joint national committee on prevention, detection, evaluation, and treatment of high blood pressure; national high blood pressure education program coordinating committee. The seventh report of the joint national committee on prevention, detection, evaluation, and treatment of high blood pressure. JAMA 2003;289:2560-72.

5 Zanchetti A, Cifkova R, Fagard R, for the Guidelines Committee, et al. 2003 European Society of Hypertension-European Society of Cardiology guidelines for the management of arterial hypertension. J Hypertens 2003;21:101 1-53.

6 Nichols WW, O'Rourke MF. McDonald's blood flow in arteries, 4th ed. London: Arnold, 1998.

7 Lakatta EG, Levy D. Arterial and cardiac aging: major shareholders in cardiovascular disease enterprises. Part l: aging arteries: a "set up" for vascular disease, Circulation 2003; 107:139-46.

8 Van Bortel LM, Struijker-Boudier H, Safar ME. Pulse pressure, arterial stiffness and drug treatment of hypertension. Hypertension 2001;38:914-21.

9 Pepine CJ, Nichols WW, Curry RC Jr, et al. Aortic input impedance during nitroprusside infusion: a reconsideration of afterload reduction and beneficial action. J Clin Invest 1979;64:643-54.

10 Gundel W, Cherry G, Rajagopulum B, et al. Aortic input impedance in man: acute response to vasodilator drugs. Circulation 1981;63:1305-14.

11 Merillon JP, Fontenier G, Lerallut JF, et al. Aortic input impedance in heart failure: comparison with normal subjects and its changes during vasodilator therapy. Eur Heart J 1984;5:447-55.

12 Ting CT, Brin KP, Lin SJ, et al. Arterial hemodynamics in human hypertension. J Clinic Invest 1986;78:1462-71.

13 Binkley PF, Van Fossen DB, Nunziata E, et al. Influence of positive inotropic therapy on pulsatile hydraulic load and ventricular-vascular coupling in congestive heart failure. J Am Coll Cardiol 1990;15:1127-35.

14 Yaginuma T, Avolio AP, O'Rourke MF, et al. Effect of glyceryl trinitrate on peripheral arteries alters left ventricular hydraulic load in man. Cardiovasc Res 1986;20:153-60.

15 Fitchett DH, Simkus GJ, Beaudry JP, et al. Reflected pressure waves in the ascending aorta: effect of glyceryl trinitrate. Cardiovasc Res 1988;22:494-500.

16 O'Rourke MF, Safar ME, Dzau V, eds. Arterial vasodilation: mechanisms and therapy. London: Edward Arnold, 1993.

17 O'Rourke MF, Staessen JA, Vlachopoulos C, et al. Clinical applications of arterial stiffness; definitions and reference values. Am J Hypertens 2002; 15:426-44.

18 Kass DA, Shapiro EP, Kawaguchi M, et al. Improved arterial compliance by a novel advanced glycation end-product crosslink breaker. Circulation $2001 ; 104: 1464-70$.

19 Mitchell GF, Izzo JL, Lacourciere Y, et al. Omapatrilat reduces pulse pressure and proximal aortic stiffness in patients with systolic hypertension: results of the conduit hemodynamics of omapatrilat international research study. Circulation 2002; 105:2955-61. 
20 Mitchell GF, Izzo JL. Evaluation of arterial stiffness. In: Izzo JL, Black HR, eds. Hypertension primer, 3rd edn. London: Lippincott Williams \& Wilkins, 2003:351-5.

21 Stokes GS, Barin ES, Grilfillan KL. Effects of isosorbide mononitrate and All inhibition on pulse wave reflection in hypertension. Hypertension 2003;41:297-301.

22 Chen C-H, Ting CT, Lin SJ, et al. Different effects of fosinopril and atenolol on wave reflections in hypertensive patients. Hypertension 1995;25:1034-41.

23 Bank AJ, Kaiser Dr. Smooth muscle relaxation: effects on arterial compliance, distensibility, elastic modulus and pulse wave velocity. Hypertension 1998;32:356-9.

24 Jiang X-J, O'Rourke MF, Jin W, et al. Quantification of glyceryl trinitrate effect through analysis of the synthesised ascending aortic pressure waveform. Heart 2002;88: 143-8.

25 Kelly RP, Millasseau SC, Ritter JM, et al. Vasoactive drugs influence aortic augmentation index independently of pulse-wave velocity in healthy men. Hypertension 2001;37:1429-33.

26 Pauca A, O'Rourke M, Kon N. Prospective evaluation of a method for estimating ascending aortic pressure from the radial artery pressure waveform. Hypertension 2001;38:932-7.

27 Pauca AL, Wallerhaupt SL, Kon ND, et al. Does radial artery pressure accurately reflect aortic pressure? Chest 1992;102:1193-8.

28 Kleinman B, Powell S, Kumar P, et al. The fast flush test measures the dynamic responses of the entire pressure monitoring system. Anesthesiology 1992;77:1215-20.

29 Murgo JP, Westerhof N, Giolma JP, et al. Aortic input impedance in norma man: relationship to pressure wave forms. Circulation 1980;62:105-16.

30 London G, Guerin A, Pannier B, et al. Increased systolic pressure in chronic uremia: role of arterial wave reflections. Hypertension 1992;20:10-9.
31 Carroll JD, Shroff S, Wirth $P$, et al. Arterial mechanical properties in dilated cardiomyopathy: aging and the responses to nitroprusside. J Clin Invest 1991;87:1002-9

32 Safar ME, Toto-Moukouo JJ, Bouthier JA, et al. Arterial dynamics, cardiac hypertrophy and anti-hypertensive treatment. Circulation 1987;75:1156-61.

33 Kinlay S, Creager MA, Fukumoto $M$, et al. Endothelium-derived nitric oxide regulates arterial elasticity in human arteries in vivo. Hypertension 2001;38:1049-53.

34 Womersley JR. Oscillatory flow in arteries: the reflection of the pulse wave at junctions and rigid inserts in the arterial system. Phys Med Biol 1958;2:178-87.

35 Segers P, Stergiopoulos N, Westerhof N. Quantification of the contribution of cardiac and arterial remodelling to hypertension. Hypertension 2000;36:760-5.

36 Milnor WR. Arterial impedance as ventricular afterload. Circ Res 1975;36:565-70

37 O'Rourke MF, Taylor MG. Input impedance of the systemic circulation. Circ Res 1967;20:365-80

38 Asmar RG, London GM, O'Rourke MF, on behalf of the REASON project investigators, et al. Amelioration of arterial properties with a perindoprilindapamide very-low-dose combination. J Hypertens 2001;19:S15-20.

39 Virmani R, Avolio AP, Mergner WJ, et al. Effect of aging or aortic morphology in populations with high and low prevalence of hypertension and atherosclerosis. Am J Pathol 1991;139:1119-29.

40 Safar ME, Levy BI, Struijker-Boudier H. Current perspectives on arterial stiffness and pulse pressure in hypertension and vascular diseases. Circulation 2003; 107:2864-9.

41 Latson TW, Hunter WC, Katoh N, et al. Effect of nitroglycerin on aortic impedance, diameter, and pulse-wave velocity. Circ Res 1988:62:884-90.

42 Mackenzie J. The study of the pulse. Edinburgh: Pentland, 1902.

\section{IMAGES IN CARDIOLOGY}

\section{Interventional cardiology: it's a hairy business}

n our department several of the senior interventional cardiologists have noticed the onset of hair loss affecting both lower limbs. The panel here shows, from left to right, a junior cardiologist and two senior interventional cardiologists with pronounced atypical hair loss.

Dermatological advice suggested that the appearances are consistent with chronic occupational radiodermatitis.

Cardiac angiography is known to produce one of the largest radiation exposures of any diagnostic $x$ ray procedure.

Chronic occupational dermatitis initially causes the skin to become dry, shiny and hairless, with atrophy of the epidermis. Ulceration, fibrosis, and eventual squamous cell carcinoma may develop. The cumulative radiation dose necessary to induce chronic changes is above 10-12 Gy. For comparison, a patient may receive up to 6 Gy during a prolonged coronary angioplasty.

It is standard practice to wear lead aprons, glasses, and thyroid collars. Interestingly cardiologists' hands receive the highest radiation exposure as they are closest to the source, yet hand protection is seldom worn. The lower legs also receive considerable scatter radiation.

It is now standard practice in our department to wear lead shielding around the lower legs.

A Wiper

R Katira

D H Roberts

a_wiper@yahoo.com

No competing interests declared

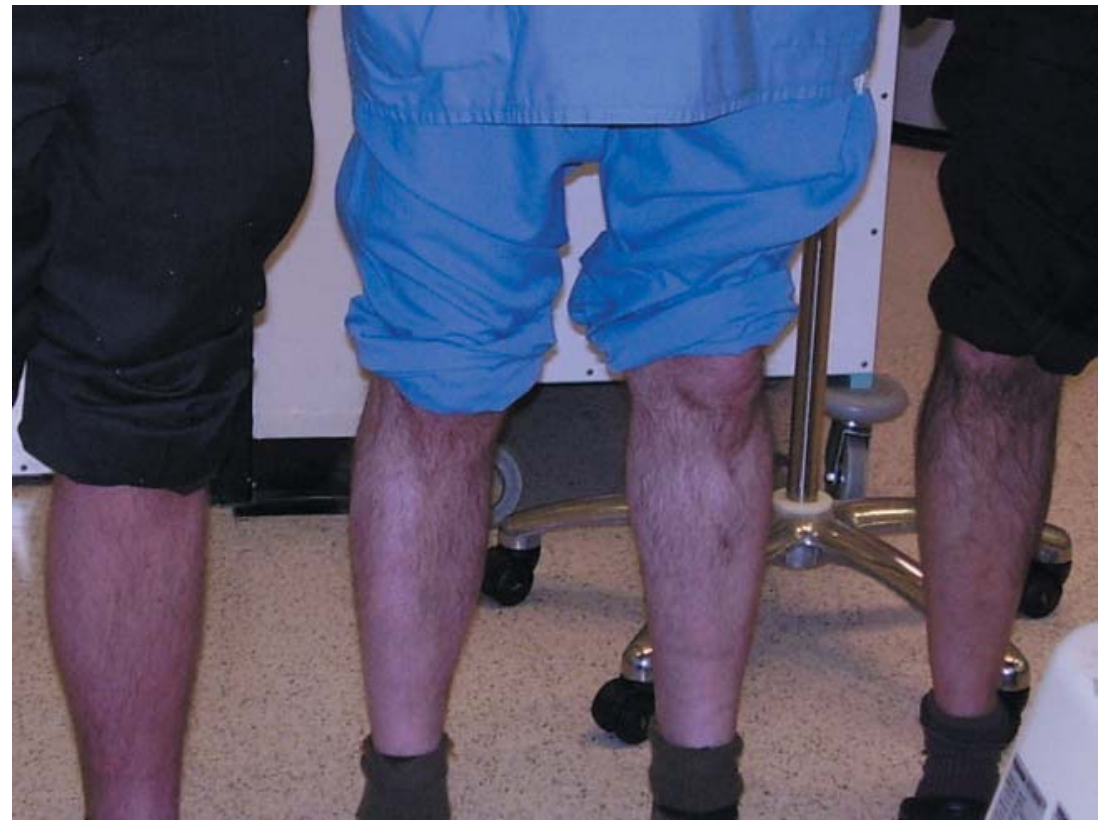

